This item was submitted to Loughborough's Research Repository by the author.

Items in Figshare are protected by copyright, with all rights reserved, unless otherwise indicated.

\title{
Lost (and found?) in translation: Key terminology in disaster studies
}

PLEASE CITE THE PUBLISHED VERSION

https://doi.org/10.1108/DPM-07-2020-0232

PUBLISHER

Emerald

VERSION

AM (Accepted Manuscript)

PUBLISHER STATEMENT

This paper was accepted for publication in the journal Disaster Prevention and Management: an international journal and the definitive published version is available at https://doi.org/10.1108/DPM-07-2020-0232

\section{LICENCE}

CC BY-NC-ND 4.0

\section{REPOSITORY RECORD}

Chmutina, Ksenia, Neil Sadler, Jason von Meding, and Amer Abukhalaf. 2020. "Lost (and Found?) in Translation: Key Terminology in Disaster Studies". Loughborough University. https://hdl.handle.net/2134/13266554.v1. 
Accepted to the Disaster Prevention and Management

Version Nov. 2020

\section{Lost (and Found?) in Translation: Key Terminology in Disaster Studies}

Ksenia Chmutina $^{1 *}$, Neil Sadler ${ }^{2}$, Jason von Meding ${ }^{3}$, Amer Hamad Issa Abukhalaf $^{3}$

$1^{*}$ Corresponding author: School of Architecture, Building and Civil Engineering, Loughborough University, UK; email: k.chmutina@lboro.ac.uk

${ }^{2}$ Centre for Translation and Interpreting, School of Arts, English and Languages, Queen's University Belfast.

${ }^{3}$ Florida Institute for Built Environment Resilience, University of Florida, USA.

\section{Abstract}

Purpose: Disaster Studies has emerged as an international interdisciplinary body of knowledge; however, similarly to other academic disciplines, its terminology is predominantly Anglophone. This paper explores the implications of translating disaster studies terminology, most often theorised in English, into other languages and back.

Design/methodology/approach: We chose six of the most commonly used (as well as debated and contested) terms that are prominent in academic, policy and public discourses: resilience, vulnerability, capacity, disaster, hazard, and risk. These words were translated into 54 languages and the meanings were articulated descriptively in cases where the translation didn't have exactly the same meaning as the word in English. We then analysed these meanings in order to understand implications of disaster scholars working between dominant and "peripheral" languages.

Findings: Our findings demonstrate that many of the terms so casually used in Disaster Studies in English do not translate easily - or at all, opening the concepts that are encoded in these terms for further interpretation. Moreover, the terms used in disaster studies are not only conceptualised in English but are also tied to an Anglophone approach to research. It is important to consider the intertwined implications that the use of the terminology carries, including the creation of a 'separate' language; power vs. communication; and linguistic imperialism.

Originality: Understanding of the meaning (and contestation of meaning) of these terms in English provides an insight into the power relationships between English and the other language. Given the need to translate key concepts from English into other languages, it is important to appreciate their cultural and ideological 'baggage'.

\section{Introduction}

In the beginning of Douglas Adams' (1979) The Hitchhiker's Guide to the Galaxy, Ford Prefect puts a Babel fish in Arthur Dent's ear and explains: '[...] if you stick a Babel fish in your ear, you can instantly understand anything said to you in any form of language. The speech patterns you actually hear decode the brainwave matrix which has been fed into your mind by your Babel fish'. Wouldn't that be great? But in the real world, translation is not so easy. Language is not univocal and there is rarely one-to-one relationship between signifiers and signified. Meaning depends on the immediate context of usage and the broader cultural context (c.f. Halliday, 2004), the pragmatics of specific interactions (c.f. Searle, 1969), the discursive environment (c.f. Fairclough, 2010), and the gradual process of language change as it evolves (Aitchison, 2012; Keller, 1994). 
Across scientific disciplines, unique language has been developed over time. Everyday expressions are replaced with "specialised" and more narrowly defined terminology. Disaster Studies has emerged as an interdisciplinary body of knowledge with a scientific literature following this pattern. The language that we use is not static; it continues to gradually evolve under the influence of policy makers, academics and practitioners. The public discourse - including the way that media covers disasters - influences and is influenced by the language that we use. The meanings of many key terms and the contexts in which they are used have shifted considerably over the years (e.g. see the etymological journey of 'resilience' by Alexander (2013)).

Despite the development of specialised terminology, many key terms do not have universally accepted definitions and remain the subject of debate among experts. At times, commonly used expressions rest on implicit assumptions which may be highly problematic - see, for example, the expression 'natural disasters' and how it wrongly attributes blame for disasters, as discussed in the seminal work by O'Keefe et al. in 1976 but is a problem that has persisted (Chmutina and von Meding, 2019; Chmutina et al., 2019). Terms can also be deployed by scholars with different disciplinary backgrounds in quite different ways (e.g. 'adaptation' in Climate Science differs from 'adaptation' in Disaster Studies).

This paper is a result of many conversations with Disaster Studies colleagues and friends from around the world. We (the authors) are all based in Anglophone academic institutions; whilst not all of us are native English speakers and some of us are fluent in other languages including Arabic, Mandarin and Russian, we predominantly rely on English in our professional lives - which is indeed reflected in the references of this paper. Yet we have been privileged to work with people from around the world, who encouraged us to think about the impact of translation in Disaster Studies on the research being done, the researchers who have to engage with literature in English, and the communities that we [are supposed to] serve. In this paper we explore the meanings of six terms that are commonly used in Disaster Studies and pose the following question: what are the implications of translating disaster studies terminology most often theorised in English into other languages?

\section{English language: behemoth, bully, thief?}

Scientific progress has truly been a global pursuit over millennia, with contributions from the scholars of North Africa, the Middle East and China proving foundational. But by World War I, French and German languages, alongside English, were dominant in many parts of the world, reflecting the ideas of Eurocentricity, imposed around the world by Western Europe over the centuries of colonisation and exploitation. From the $16^{\text {th }}$ century onwards, Western Europe expanded behind its guns and sails, to develop mercantile enterprises and "settle" new territories. With the Industrial Revolution in the $18^{\text {th }}$ Century, Western Europe virtually achieved global economic domination imposing 'Western' ${ }^{1}$ economic values of 'production' and 'growth' on regions' economies, where the 'growth' wasn't a concern before (Pilling, 2018). In the context of such domination, ethnocentricity began to take more aggressive stance, automatically treating 'other breeds' as 'lesser breeds' - and

\footnotetext{
${ }^{1}$ In this paper, what it means to be "Western" is wrapped up in the Eurocentric ideas of civilisation and progress, stemming from the time when Europeans believed themselves to be the only 'west'. Today it is used, ironically, to refer to "better", "more civilized", "more developed", when it might more easily point to achievements such as colonialism, capitalism, monotheism, racism, and patriarchy.
} 
'a sophisticated scholarship manufactured reasons why it should be so' (Goody, 2006: 6).

Eurocentrism argues that the birth and growth of modern science has only been possible solely due to intellectual, social, and cultural influences, causes, and ideas within Europe. Centuries of ideas, practices and traditions from non-Christian religions and non-Western European geographies, on the other hand, are frequently either deemed to have little value or neglected entirely. The possibility that Europe could have been crucially influenced by other cultures in constructing modern science has hardly been entertained within this outlook (Goody, 2006).

At the start of the $20^{\text {th }}$ century English gradually became the world's lingua franca as other European languages lost pre-eminence (Phillipson, 1992) - although it must be noted that English itself has absorbed vocabulary from Latin, Greek, French, Hindi, Nahuatl and many other languages. Crystal (2003) suggests that a language becomes a global language because of the power of the people who speak it. The "power" of English was initially based on political and military factors, most notably the expansion of the British Empire. The role of English as the language of industrial, financial and economic "progress" further increased its influence.

An English-language scientific hegemony creates difficulties for scholars and universities that do not use the language (Altbach, 2007), effectively excluding many from international debate, regardless of the quality of their ideas. Non-anglophone scholars who can write in high quality academic English are nonetheless compelled to express themselves using Anglophone categories, distinctions and underpinning value systems in order for their work to pass peer review. For instance, Stiftel and Mukhopadhyay (2007) demonstrate that, while the English-language urban planning literature is broadly multi-national, non-Anglophone scholarship is under-represented; Whitehand (2003) shows the same trend in geography, with Anglophone authors being over-represented in citations. To assume that citations are a purely neutral indicator of intellectual value in scholarship would therefore be unjust.

While these issues are common to many disciplines, they are particularly acute in Disaster Studies given its global scope and the central importance of transnational bodies - there is a tendency to defer to "authority", such as the United Nations, for terminology. In 1976 Lewis called for a change in the whole approach to disasters, moving away from not just a nature-centric approach to disasters, but also from the way we research and understand disasters. This was a call for a transition away from the certainties of Western scholarship. But as Gaillard (2019) argues, we have only partially met this challenge. Whilst there has been a significant shift in thinking about disasters, 'disaster studies continue to be dominated by Western scholars, whatever the location of the disaster or study area' (Gaillard, 2019:10).

\section{The role of translation in Disaster Studies}

Western scholars largely rely on English as their communication medium. What we commonly see in Disaster Studies is research conceptualised in English, designed in English, translated into a local language for data collection, translated back to English for analysis, and finally written about in a language (English) that the research 'subjects' may not be able to understand. This greatly limits the impact of research beyond academia while also effectively preventing the subjects of research from contesting the ways in which they are represented by academics. Many disaster scholars have been trying to challenge this by arguing that the research must be informed by local realities (as 
highlighted in the collectively written Disaster Studies Manifesto published in 2019) ${ }^{2}$ - one of which is the language.

In this context, translation takes on particular importance. Disaster Studies scholars often rely on translation and interpreting ${ }^{3}$ to learn about the contexts that they study. This can cause issues similar to those discussed in anthropology, in which researchers are both excessively dependent on the perspective of a limited number of 'interpreter-informants' and unable to independently verify information (c.f. Owusu, 1978). It is also through translation, principally out of English, that Disaster Studies research is made accessible to policy makers and the general public in the non-Anglophone world. Meanwhile, translation from other languages enables scholars, practitioners, and the general public, to enter Anglophone debates.

It has long been recognised that there can rarely be perfect equivalence when translating between languages (Nida, 1964; House, 1977; Baker, 1993; Koller, 1995). In light of this, Venuti $(1995,1998)$ identifies two basic orientations in translation: 'domestication' and 'foreignisation'. A domesticating approach seeks to render translation invisible, masking the origins of a text in another language by precisely following those of the receiving, or 'target', culture. A foreignising approach, on the other hand, seeks to emulate the structures, rhetorical form and style of the original, or 'source', culture even if this means going against dominant norms in the target language. This distinction matters, Venuti argues, because to domesticate means not only adopting the linguistic norms of the target language but also assimilating cultural values.

To foreignise is to challenge both existing target language norms and cultural values, allowing for disruptive encounters with alterity (otherness). These practices are in turn intimately connected to broader questions of power and inequality; content is much more frequently translated from dominant languages - especially English - into other languages, than the reverse. Translation from dominant into 'peripheral' languages ${ }^{4}$ is typically foreignising and prioritises the reproduction of source language structures. Rather than seeking dictionary equivalents or 'carrying across' a nonlinguistic meaning, foreignising translation deliberately seeks to impede fluency in order to draw attention to the discontinuities between languages. When translating from a dominant language and particularly in a field of research like Disaster Studies, where so much work takes place in the non-Anglophone context - this can be a colonizing approach. But employed in the most positive way foreignising can allow new possible meanings and connotations to come into view which otherwise remain hidden. In philosophy, for example, influential translations of European thinkers such as Heidegger $(1982,2010)$, Habermas (1989), Derrida $(1974,1978)$ and Foucault $(1977,2002)$ hew very closely to the structures and word choice of the German and French source texts. This has contributed to their being regarded as difficult texts in English (Bennett, 2017) but also helped to prevent their ideas being easily subsumed within established ways of thinking in Anglophone philosophy. But these are the exceptions. When translation takes place from 'peripheral' languages into English, it is primarily domesticating. Deference is paid to the status of the dominant language

\footnotetext{
2 The 'Power, Prestige \& Forgotten Values: A Disaster Studies Manifesto' has so far been signed by over 420 scholars; its full text can be found here: https://www.ipetitions.com/petition/power-prestige-forgotten-values-a-disaster

${ }^{3}$ Interpreting' is used to refer specifically to oral interlingual mediation; 'interpretation' is used to refer to the broader activity of interpreting a statement or text without necessarily trying to reproduce it in another language.

4 The term 'peripheral languages' refers to all languages which do not have a central position in the global language system, with the result that there is both little translation from them into dominant languages - e.g. Yoruba into English - as well as little interaction between them that does not take place via a dominant language serving as a pivot language - e.g. Russian and Vietnamese speakers communicating through English. As such, the category includes the vast majority of the world's languages (cf Cronin, 1998).
} 
and the structures of the source language are frequently abandoned in favour of fluent, easily read translations which nonetheless reflect little of the otherness of their source texts.

As we were writing this paper, we asked ourselves: Is common terminology useful? Does it reflect the intended and the perceived meaning? What is the best way forward? Whilst we don't have the definitive answers to these questions, by investigating the translation of disaster terminology we hope to encourage Disaster Studies scholars to become more attuned to the complex social construction of disasters - in different ways, in different places, conceptualised uniquely - and increase the meaning of their research by building on a fair dialogue (that requires consciousness and trust) and redressing power relationships (Freire, 1970; Gramsci, 1971).

\section{Methodology}

In order to explore the implications of Disaster Studies' terminology into different languages, we chose six of the most commonly used (as well as debated and contested) terms that are prominent in all disaster-related sources, from international policy to academic publications as well as news reports: resilience, vulnerability, capacity, disaster, hazard, and risk. Using social media (Twitter and Facebook) and personal and professional networks, we requested translations of these terms from English into other languages. In the social media posts, we explained what we were investigating and how the translations would be used, to avoid any misinterpretation of the purpose of the data collection and a consequential exploitive process of knowledge extraction; all the translations were submitted voluntary. The languages were not predetermined - instead, we hoped for a diverse representation of languages from around the world. The words were written in the original language, and the meanings were then relayed to us descriptively in cases where the translation didn't have exactly the same meaning as the word in English.

Overall, we received translations into 54 languages. ${ }^{5}$ Some languages featured more than once, and in the cases where the translations differed, we requested a third opinion. Many participants noted particularities about the language they were translating into; for example, that a particular translation would only be used in an academic setting, whereas in 'real' life another word would be used. In some cases, we also received notes stating that a certain word would only be used in a certain context (e.g. in an informal conversation, in a conversation between people of a certain group etc.) or explaining how the word is used and by who.

The collected meanings were collated in an Excel spreadsheet and then compared in order to understand differences and similarities between them. It was critical that we do not just emphasise the difference and similarities but instead engage with the existing translation theories - as well as disaster scholarship. This is reflected in the authorship of the paper. The results of this analysis are presented in the following sections.

\section{Terminology}

In this section, we will provide a brief overview of the meanings of and debates around the terms that we are discussing in this paper (the summary is presented in Table 1). We will also demonstrate

\footnotetext{
${ }^{5}$ Afrikaan, Arabic, Armenian, Bahasa Indonesia, Bahasa Malaysia, Bulgarian, Cantonese, Chichewa, Chinese (Mandarin), Farsi, Finnish, Flemish, French, Georgian, German, Greek, Guarani, Hausa, Hindi, Hungarian, Ibibio, Igbo, Ikwerre, Italian, iTaukei (traditional Fijian), Japanese, Kalabari, Kazakh, Kikuyu, Korean, Luo, Macedonian, Nepali, Ogoni, Persian, Peul, Portuguese, Russian, Serbian, Sesotho, Spanish, Swahili, Swedish, Tagalog, Thai, Tswana, Turkish, Twi, Urdu, Vietnamese, Welsh, Xhosa, Yoruba, Zulu
} 
some of the translations to emphasise that the terms used in disaster studies are not only conceptualised in English but are also tied to a particularly Anglophone approach to research (Kelman, 2018; Gaillard, 2019).

\section{TABLE 1 GOES AROUND HERE}

Resilience is one of the latest additions to the Disaster Studies lexicon yet it is widely debated concept in the Anglophone urban and risk-related disciplines; its meanings evolve and change as the concept is continually reified by academics, politicians, decision-makers and others. Its use has been widely promoted by various non-governmental organisations (often as a synonym to 'security' albeit with more positive connotation), and over the years resilience has become 'a panacea for a spectacular variety of contemporary social and environmental ills' (Zebrowski, 2020, p.73). The $\mathrm{UNDRR}^{6}$ defines resilience as 'The ability of a system, community or society exposed to hazards to resist, absorb, accommodate, adapt to, transform and recover from the effects of a hazard in a timely and efficient manner, including through the preservation and restoration of its essential basic structures and functions through risk management' (UNDRR, 2017). In Anglophone academic literature resilience has generally been defined in two ways: as a desired outcome, or as a process leading to a desired outcome, with the definitions largely focusing on the ideas of the ability to selforganise; and the capacity to learn, to change and to adapt - although these foci change swiftly due to the malleability of the term (Wang et al., 2019; Sanchez et al., 2016). It is also important to note that resilience, as a term, is highly political, and thus its 'promotion' in the non-Western world is rooted in neoliberal ideas of 'growing the wealth of the poor' (Bracke, 2016, p.52) and using it as a pathway to (re)build the capacity of financial systems and national economies in the aftermath of disasters, thus reinstating the pre-disaster conditions.

Translating the term resilience is not straightforward, as one might expect given its ambiguity even in English. The words used as a translation for 'resilience' range from adaptability, elasticity and flexibility to firmness, endurance and strength, to resistance, survivability and tolerance; a range of meanings sometimes appears within the same language. In Afrikaans, the word veerkragtigheid ${ }^{7}$ is very descriptive, meaning to be 'spring-like' (literally translating as 'bouncy-bouncy', causing a native speaker to think of an athlete ready to jump). This meaning may seem to be related to the idea of resilience as bouncing back, however it emphasises the change of direction or getting over an obstacle without the obstacle having an impact on someone].

Vulnerability is another contested yet widely used term. The UNDRR (2017) defines vulnerability as 'the conditions determined by physical, social, economic and environmental factors or processes which increase the susceptibility of an individual, a community, assets or systems to the impacts of hazards.' The term vulnerability has shifted the focus from hazards to the indigenous and exogenous origins that made communities unsafe as well as people's capacity to recover from loss (Lewis, 2014; Wisner, 2016; Bankoff, 2019). But it is also important to remember that vulnerability can be employed - or perceived to do so - in order to portray certain localities and groups of people as fundamentally unstable, unsafe and in need of intervention (Bankoff, 2001) as 'those who need help, [...] poor victims or passive recipients' (Heijmans, 2004, p. 127).

\footnotetext{
${ }^{6}$ Herein we will use the UNDRR definitions as these are perceived as acceptable among most of Disaster Scholars.

${ }^{7}$ We appreciate that only few readers will be able to actually understand the words written in different languages as we present them in this section, but it serves to reinforce the terms used in these other languages are not just different labels for precisely the same concepts.
} 
When translated, the term overwhelmingly reflected this meaning of weakness - many languages use the word as a state of being exposed or needy, being weak, or being in trouble. In Chichewa, there two different words that have two meanings: as disaster jargon, umbalambanda means 'to be without anything'; in daily life kukhala pa mtetete is used to describe a lack of protection. Many translations we received are also related to the word 'wound' (which, indeed, is derived from the late Latin vulner-, vulnus). Drawing on Bankoff (2011), disaster scholars continue to push back on a "weakness-based" framing of vulnerability as something that can be insulting (Marino and Faas, 2020), or indeed misses out on the emancipatory potential of the concept (von Meding and Harmon, 2020).

Capacity is probably one of the most overlooked concepts in disaster studies (although a popular one among practitioners!). Whilst many appreciate the role of social capital, skills, traditional knowledge or alternative income-generating activities in increasing resilience to natural hazards, the focus of the research tends to inevitably move towards vulnerability (that is often albeit incorrectly seen as an opposite end of the spectrum) or resilience (which is sometimes seen as the same idea). The UNDRR (2017) defines capacity as 'the combination of all the strengths, attributes and resources available within an organization, community or society to manage and reduce disaster risks and strengthen resilience'. This definition emphasises that capacity is about how individuals and communities make gradual adjustments to cope with environmental changes caused by natural hazards without modifying the fundamentals of their social organisation (Gaillard, 2007).

When translated, we yet again found a range of meanings emerging, including the ability to cope with something, capability, competency, strength, wherewithal, preparedness, and even power and position of authority. This range of meanings somewhat reflects on what constitutes capacity. In Russian, for instance, достаточность сил и средств means 'sufficiency of forces and capital', whereas Vietnamese khả năng means 'availability of something to deal with or solve [something else]'.

The other three terms explored for this paper - risk, hazard, and disaster - are less contested in Anglophone academe - but these have proven to be the hardest to translate. The UNDRR (2017) provides the following definitions: [Disaster] risk is 'the potential loss of life, injury, or destroyed or damaged assets which could occur to a system, society or a community in a specific period of time, determined probabilistically as a function of hazard, exposure, vulnerability and capacity'. Hazard is 'a process, phenomenon or human activity that may cause loss of life, injury or other health impacts, property damage, social and economic disruption or environmental degradation'. Disaster is 'a serious disruption of the functioning of a community or a society at any scale due to hazardous events interacting with conditions of exposure, vulnerability and capacity, leading to one or more of the following: human, material, economic and environmental losses and impacts.'

In English, the roles of severity and risk factors are significant in the definition of disaster: severity signifies a substantial departure from a mean or trend, and the fundamental determinants of hazards comprise location, timing, magnitude, and frequency; risk factors are related to the threshold determined by the combination of the lowest limit at which physical forces can cause damage (Alexander, 2000). A disaster is thus not just an occurrence of a hazard. It is through these nuances that an argument is built against the use of the misnomer 'natural disasters' (see Chmutina and von Meding, 2019). 
However, in many languages these terms are used as synonyms and do not convey such intellectual nuances. Meaning begins to be obscured. The words used for hazard and risk are the same in many languages, their meaning reflecting chance or randomness. Other meanings include danger, destruction, disturbance, trouble, or fear. In some cases, these words have separate translations: for instance, in Hausa, the word kasada means 'a chance', in Bulgarian puck means 'gambling', but the general connotation of these meaning is that something bad might happen. Disaster also often does not have a separate term - or it does not translate at all. For instance, in Urdu, there is no conception of a "disaster"; people instead use specific hazards, such as floods or earthquake, as an event that caused damages and destructions. Where is can be translated, the meaning is similar to that of risk and hazard: something bad is happening. In Kalabari, Fi na fa boko literally translates back into English as 'the door of death and loss'.

\section{Implications of the 'Anglophone squint' ${ }^{8}$}

These 6 disaster terms are both prescribed meaning and contested in English, predominantly. This provides an interesting insight into linguistic power relationships. Our data show that Anglophone debates could be greatly enriched by allowing non-Anglophone perspectives to enter. Take resilience as an example: the Afrikaans term veerkragtigheid gives a connotation of 'bouncing' or 'jumping' while the Chichewa/Chewa term kupilira connotes standing firm and withstanding hardship. The differences between the way key notions are conceptualised in different linguistic contexts can be subtle or obvious. We should learn about these alternative conceptions in order to expand prevalent understandings in the Anglophone world. But herein lies the danger. If a domesticating approach to translation is followed when we move from other languages into English, the alterity of such perspectives is largely neutralised - it comes to seem as if there is no difference between veerkragtigheid and resilience.

A foreignising approach, on the contrary, might mean choosing less commonly used English terms or 'thickening' the translation with commentary to explain the connotations of the term used in another language (Appiah, 2000). Translating veerkraftigheid into English as 'springing back', for example, would run against the discursive norms of Disaster Studies and have a destabilising effect, compelling a reader accustomed to Anglophone terminology to stop and think. This creates a space for alternative ways of conceptualising very familiar terms in new and different ways. Provoking disruption in this way allows translation to become creative, innovative and productive rather than simply a barrier to be overcome. Rather than seeking dictionary equivalents or 'carrying across' a non-linguistic meaning, foreignising translation deliberately seeks to create opportunities to consider new meanings that might otherwise remain hidden - learning that resilience is conceptualised in terms of springing back in Afrikaans allows this meaning to enter into and enrich the English term resilience.

But adopting a foreignising translation approach out of English may create as many problems as it solves. At best, it may fail to recognise and take advantage of existing terms and ways of conceptualising disasters which are better suited to local geography, culture, history and society and instead impose a hegemonic Western perspective. At worst it may also result in 'translationese' (Volansky et al., 2015; Baker, 1992), which is incomprehensible beyond a narrow circle of specialists already familiar with the idiosyncrasies of Anglophone academic and NGO discourse. Thus, before

\footnotetext{
${ }^{8}$ As coined by Whitehand (2005)
} 
using any Disaster Studies terminology, it is important to consider the intertwined implications that the use of the terminology carries:

- Creation of a 'separate' language: Too often terminology is only understood and 'correctly' used by certain groups of people (e.g. NGO workers, academics); this hinders clear communication between those who are communicating and those who receive communication. The UN produces glossaries to standardise vocabulary that are then translated into the UN languages. This, of course, allows standardisation of vocabularies among policy and practice, but also creates silos of 'disaster speak' and 'real language', thus separating disaster studies from people's daily concerns, as the language does not reflect the reality - and therefore the research does not benefit the subjects of the research. Making certain concepts plausible does not necessarily translate into local practices. The language that makes certain discourses legitimate and compelling for decision makers or dominant social groups may produce the exact opposite effect for marginalised groups (Nicholls and Uitermark, 2018). Too often the focus on the concept itself obstructs what is happening on the ground and obfuscates existing vocabularies. For instance, the term resilience did not exist in Nepali in a way that it is used in disaster context. It had been previously introduced with a meaning of 'community or country developing in the right and proper direction'. Such meaning is influenced by the international 'resilience' agenda (largely let by the World Bank and the IMF). The use of resilience in this context could imply that if a community or a country is not 'resilient', it is not developing 'properly' - which feeds into the neoliberal thinking of the ability of being able to survive - and be productive - under the conditions of destitution (Brecke, 2016, P. 61), or else be treated as 'underdeveloped'.

- Power vs. communication: There is a distinction between the power behind language and the power of language (Ng and Deng, 2017). In the former, language reveals the influence and power of the speaker. The latter reflects the collective/historical power of the language community that uses it. In both cases, language use both reflects and reinforces broader power imbalances (Fairclough, 2010; Van Dijk, 1998; Wodak, 1997). This creates a tension as information may be intentionally obscured or may create contrasting conditions of legitimacy. The language is dominated by 'proper' terminology developed by think-tanks and experts who are often employed by the decision makers, thus making these terms politically powerful, regardless of its usefulness in any language other than English. Familiarity with the terms in English (and with the concepts they encode) confers insider status and a sense of belonging; the ability to deploy them empowers their users (Thorne 2006). The term vulnerability demonstrates this point well: 'vulnerability reduction' has been at the forefront of the developmental agenda for decades, implying that people are 'helpless'. This allows justifying interventions and attracting resources. In Georgian, for instance, the word used for vulnerability is not a part of the 'real life' language, however over the years many communities have learnt that the aid and donor programmes that use this term are there to carry out some sort of improvements in disaster preparedness or awareness raising. These efforts do not change the root causes of disasters - and vulnerability remains.

- Linguistic imperialism: Domination of Western and, later, Anglophone ontologies in Disaster Studies has already been noted earlier in this paper. Language is an important tool for maintaining influence and power over other societies and their resources. Anglophone domination of the academic and policy language manifests imperialism, dominance and 
hegemony, not only geographically but also ideologically (Bankoff, 2001). This dominance of a culturally and linguistically 'naturalised' Anglo-centric view has heavily informed the development of disaster knowledge and practice. Such ethnocentricity, furthermore, has resulted in tacit assumptions regarding the general applicability and transferability of knowledge beyond English language speaking contexts. Consequently, other culturally situated notions of hazards, risk, or disasters have been comparatively marginalised. In many languages these terms are all used to imply danger, but this is too broad for the academic debate. Instead of finding ways of communicating the message for instance, about the social construct of disasters, we might give up on communicating about it at all. Seldom do we deploy (or even realise) the appropriate local language to covey meaning when local knowledges are often seen as inferior. By trying to adopt terms that are widely used in English, rather than challenging the hegemony of academic English and its attendant cultural values, Disaster Studies often end up reinforcing it by suggesting that other languages have little new to say.

\section{Conclusions}

Winston Churchill once coined the humorous euphemism 'terminological inexactitudes' instead of 'lies'. We encountered various 'terminological inexactitudes' in this study, along with the ambiguities arising from the translation of Disaster Studies jargon.

As demonstrated in the paper, translation often lays bare the taken-for-granted assumptions and norms of both our own language and that of others. Language is always characterised by social, stylistic and geographical diversities and it is sensitive to the historically changing practices (Carlucci, 2015). Indeed, the translations of the terms that we have used as examples here in some ways approximate the meanings articulated by 'institutional', Anglophone definitions. But it is important to remember that all these terms relate to Western concepts shaped at a particular historic juncture by a particular historic perspective; as a consequence, they can only mean what they do from within the prevailing socio-economic system (Bankoff, 2019; Gaillard, 2019). Language is irreducibly intertwined with culture. Thus, language is the key means of understanding the perspectives of different social groupings and their various members. Even in countries with English as an official language, the contextual nuances of daily lives are not often reflected in the way that technical terminology is used.

Language has always been a political tool to exert influence, strength, and power - and in a world that is becoming more and more globalised and where decisions are made and communicated at a supranational level, the role of translation and interpreting becomes critical. It has the power to not only 'decide' what information is to be conveyed, but also who is to be informed. The power of language lies in its ability to create what is 'real' (Farquhar and Fitzsimons, 2011) - the way we speak establishes what we consider possible (Foucault, 2001) - and this gives language significant power. Language thus reflects not only culture but also politics. In the terms of this study, we highlight a need to take the question of translation and interpreting seriously if it is to redress power imbalances rather than reinforce status quo relations. At its most basic, this means resisting the tendency to unthinkingly foreignise when translating from English into other languages, but to intentionally foreignise when moving from other languages into English. 
In order to 'resist the hegemony of Western scholarship and to relocate disaster studies within the realm of its original political agenda' (Gaillard, 2019:7), it is important that Disaster Studies scholars start examining the political, historical and cultural roots of disasters within their own languages as well as critically examining the English language as a lingua franca. Given the need to translate key Disaster Studies concepts from English into other languages, it is important to appreciate their cultural and ideological 'baggage'. It is essential that local actors and stakeholders apply their own critical perspectives to the language which is being used - whichever language that is - in order to make the terminology meaningful and relevant. Of course, the local approaches can also be highly problematic as they decontextualise and homogenise the local power relationships (Freire, 1970; Maskrey, 1984; Chambers, 1998) that need to be acknowledged. But when Disaster Studies scholars study contexts distant from their own experience, it is necessary to recognise the value of local conceptual frameworks. No one can be expected to learn every language in the world and all translation is unavoidably domesticating in the sense that it uses the words, grammar and conceptual frameworks of one language to represent another. Nonetheless, to use foreignising techniques when translating into English is to acknowledge the reality and validity of perspectives originally articulated in other languages while also making them visible.

It is acceptable to be 'lost' in translation as it allows us to accept both the contingency of language and the impossibility of fully encapsulating otherness within our own realities (because remember that 'by effectively removing all barriers to communication between different races and cultures [the Babel fish] has caused more and bloodier wars than anything else in the history of creation' (Adams, 1979)). Recognising this contingency creates space for non-Western perspectives to enter and enrich Anglophone discussions, facilitating genuine dialogue rather than a one-way, quasi-imperialist imposition of ideas.

This paper provides a mere glance at a very small sample of the terminology that matters and of the languages that are used around the world - and we hope that others, 'insiders' from inside or outside the region, will take the process further. Attempts to rectify 'Anglophone squint' require multi-directional efforts by both Anglophones and non-Anglophones - and there are benefits for all.

\section{Acknowledgements}

We would like to thank all the friends and colleagues from around the world who have helped us to compile the material for the paper, and the participants of the 'Lost in Translation' session at the $8^{\text {th }}$ International i-Rec Conference in Gainesville, Florida, 2019, for the rich conversation about disaster language translation. We also want to thank the reviewers who provided insightful and supportive comments and constructive critique that helped us to finetune our argument.

\section{References}

Adams, D. (1979), The Hitchhikers' Guide to the Galaxy, Pan Books, UK.

Aitchison, J. (2012) Language Change: Progress or decay? 4th ed. Cambridge University Press,Cambridge.

Alexander, D. (2000), Confronting Catastrophe, Terra Publishing, London. 
Alexander, D. (2013), "Resilience and disaster risk reduction: an etymological journey", Natural Hazards and Earth System Science, Vol 13, pp. 2707-2716.

Altback, P.G. (2013), "The Imperial Tongue: English as the Dominating Academic Language", Economic and Political Weekly, Vol. 42 No. 36, pp. 3608-3611.

Appiah, K.A. (2000), "Thick Translation", Venuti, L. (Ed.), The Translation Studies Reader, Routledge, London \& New York, pp. 417-429.

Baker, M. (1992), In Other Words, Routledge, London \& New York.

Baker, M. (1993), "Corpus Linguistics and Translation Studies: Implications and applications", Francis, G., Baker, M. and Tognini Bonelli, E. (Eds.), Text and technology: in honour of John Sinclair, John Benjamins, Amsterdam.

Bankoff, G. (2001), “Rendering the World Unsafe: 'Vulnerability' as Western Discourse”, Disasters, Vol.25 No.1, pp. 19-35.

Bankoff, G. (2019), "Remaking the world in our own image: vulnerability, resilience and adaptation as historical discourses", Disasters, Vol 43 No 2, pp.221-239.

Bennett, K. (2017) Foucault in English: The politics of exoticisation. Target, Vol 29 No 2, pp.222-243.

Bracke, S. (2016), "Bouncing back: Vulnerability and resistance in times of resilience", Butler, J., Gambetti, Z. and Sabsay, L. (Eds.) Vulnerability in resistance, Duke University Press, Durham \& London, pp. 52-75.

Carlucci, A. (2015), "Gramsci, language and pluralism”, McNally, M. (Ed.), Antonio Gramsci, Palgrave Macmillan, UK, pp. 76-96.

Chambers, R. (1998), “Foreword to the Myth of Community', Gujit, I. and Shah, M.K. (Eds.), Myth of Community, Practical Action, UK, pp. xvii-xx

Chmutina, K. and von Meding, J. (2019), “A dilemma of language: 'natural disasters' in academic literature", International Journal of Disaster Risk Science, Vol 10, pp. 283-292.

Chmutina, K., von Meding, J., Bosher, L. (2019), "Language matters: dangers of the "natural disaster" misnomer", Contributing paper to the Global Assessment Report (GAR) 2019, UNDRR, available at: https://www.preventionweb.net/publications/view/65974

Cronin, M. (1998), "The cracked looking glass of servants: Translation and minority languages", The Translator, Vol 4 No 2, pp. 145-162.

Crystal, D. (2003), English as a global language, Cambridge University Press, Cambridge.

Derrida, J. (1974) Of Grammatology, Johns Hopkins University Press, Baltimore \& London

Derrida, J. (1978) Writing and Difference, Routledge \& Kegan Paul, London \& New York

Fairclough, N. (2010), Critical Discourse Analysis: The critical study of language, 2nd ed., Routledge, Oxford \& New York.

Farquhar, S. and Fitzsimons, P. (2011), "Lost in Translation: The power of language", Educational Philosophy and Theory, Vol. 43 No.6, pp. 652-662

Foucault, M. (1977) Discipline and Punish: The birth of the prison, Allen Lane, London. 
Foucault, M. (2001), "The Subject and Power", Faubion, J. (Ed.), Power: The essential work, Penguin, London, pp. 326-348

Foucault M (2002) The Order of Things: Archaeology of the human sciences, Routledge, London \& New York

Freire, P. (1970), Pedagogy of the oppressed, Herder and Herde, New York.

Gaillard, J.C. (2007), "Resilience of traditional societies in facing natural hazards", Disaster Prevention and Management, Vol 16 No 4, pp.522-544

Gaillard, J.C. (2019), “Disaster studies inside out”, Disasters, Vol. 43 No. S1, pp. S7-S17.

Goody, J. (2006), The Theft of History, Cambridge University Press, Cambridge.

Gramsci, A. (1971), Selections from the Prison Notebooks, International Publishers, New York.

Habermas, J. (1989), The Structural Transformation of the Public Sphere: An inquiry into a category of bourgeois society, The MIT Press, Cambridge, MA.

Halliday, M.A.C. (2004), An Introduction to Functional Grammar, $3^{\text {rd }}$ Ed, NY: Hodder Arnold.

Heidegger, M. (1982) Basic Problems of Phenomenology,,Indiana University Press, Bloomington

Heidegger, M. (2010) Being and Time, State University of New York Press, Albany, NY

Heijmans, A. (2004), "From vulnerability to empowerment”, Bankoff, G., Frerks, G. and Hilhorst, D. (Eds.), Mapping vulnerability: Disasters, development and people, Earthscan, London, pp. 115-127.

House, J. (1977), A Model for Translation Quality Assessment, TBL Verlag Gunter Narr, Tübingen.

Keller, R. (1994) On Language Change: The invisible hand in language,: Routledge, Abingdon, Oxon \& New York

Kelman, I. (2018), "Lost for words amongst disaster risk science vocabulary?", International Journal of Disaster Risk Science, Vol. 9, pp. 281-291.

Koller, W. (1995), "The Concept of Equivalence and the Object of Translation Studies", Target, Vol 7 No 2, pp. 191-222.

Lewis, J. (1976), "The precautionary planning for natural disaster", Foresight, Vol 2 No 2, pp. 7-10

Lewis, J. (2014), "The susceptibility of the vulnerable: Some realities reassessed", Disaster Prevention and Management, Vol 23 No 1, pp. 2-11.

Marino, E. and Faas, A.J. (2020), "Is vulnerability an outdated concept? After subjects and spaces", Annals of Anthropological Practice, Vol. 00 No. 0, pp. 1-13.

Maskrey, A. (1989), Disaster Mitigation. A Community Based Approach, Oxfam, Oxford.

Ng, S. H. and Deng, F. (2017) Language and Power, Oxford Research Encyclopedias: Communication, available at:

https://oxfordre.com/communication/view/10.1093/acrefore/9780190228613.001.0001/acrefore$\underline{9780190228613-e-436}$ 
Nicholls, W. and Uitermark, J. (2018), "Counter publics and counter spaces", Enright, T. and Rossi, U. (Eds.), Urban Political, Palgrave Macmillan, Switzerland, pp. 247-268.

Nida, E. (1964), Toward a Science of Translating: With special reference to principles and procedures involved in Bible translating. E. J. Brill, Leiden.

O'Keefe, P., Westgate, K. and Wisner, B. (1976), "Taking the naturalness out of natural disasters", Nature, Vol 260, pp. 566-567.

Owusu, M. (1978), "Ethnography of Africa: The Usefulness of the Useless", American Anthropologist, Vol 80 No 2, pp.310-334

Phillipson, R., (1992) Linguistic imperialism, Oxford University Press, Oxford.

Pilling, D. (2018), The growth delusion, Bloomsbury, London.

Sanchez, A.X., van der Heijden, J. and Osmond, P. (2018), "The city politics of an urban age: urban resilience conceptualisations and policies", Palgrave Communication, Vol 4 No 25, pp. 1-12.

Searle, J. (1969), Speech Acts: An essay in the philosophy of language, Cambridge University Press, Cambridge.

Stiftel, B. and Mukhopadhyay, C. (2007), Thoughts on Anglo-American hegemony in planning scholarship: Do we read each other's work? The Town Planning Review, Vol 78 No 5, pp. 545-572

UNDRR (2017), Online Glossary, available at: https://www.undrr.org/terminology

Van Dijk TA (1998), Ideology: A multidisciplinary approach. London, Thousand Oaks, New Delhi: SAGE Publications.

Venuti, L. (1995), The Translator's Invisibility: A history of translation, Routledge, Abingdon, Oxon \& New York.

Venuti, L. (1998), The Scandals of Translation: Towards an ethics of difference, Routledge, New York \& London.

Volansky, V., Ordan, N. and Wintner, S. (2015), "On the Features of Translationese", Digital Scholarship in the Humanities, Vol 30 No 1, pp. 98-118.

Von Meding, J. and Harmon, H. (2020), "Who's afraid of vulnerability?", openDemocracy Transformation, $7^{\text {th }}$ June 2020 , available at https://www.opendemocracy.net/en/transformation/whos-afraid-of-vulnerability/

Wang, Y., Hulse, D., von Meding, J., Brown, M., and Dedenbach, L. (2019), “Conceiving Resilience: Lexical Shifts and Proximal Meanings in the Human-Centered Natural and Built Environment Literature from 1990 to 2018", Developments in the Built Environment, Vol 1, pp.1-19

Whitehand, J.W.R. (2005), "The problem of anglophone squint”, Area, Vol 37, No 2, pp. 228-230.

Wisner, B., 2016. Vulnerability as Concept, Model, Metric, and Tool. In: Oxford Research Encyclopaedia of Natural Hazard Science. DOI: 10.1093/acrefore/9780199389407.013.25

Wodak R (ed.) (1997) Gender and Discourse. London, Thousand Oaks, New Delhi: SAGE Publications. 
Accepted to the Disaster Prevention and Management Version Nov. 2020

Zebrowski, C. (2020), "Acting local, thinking global: Globalizing resilience through 100 Resilient Cities", New Perspectives, Vol 28 No 1, pp. 71-88. 